JEBI I

\title{
PERANCANGAN SISTEM INFORMASI PARIWISATA BERBASIS WEBSITE SEBAGAI MEDIA PROMOSI DI SINGKAWANG- KALIMANTAN BARAT
}

\author{
Designing Information System Tourism Web-Based As a Media Promotion in \\ Singkawang-West Borneo
}

\author{
Kasnur Saputra ${ }^{1}$ \\ ${ }^{1}$ Program Studi Manajemen, Fakultas Ekonomi dan Bisnis Universitas Teknologi Sumbawa \\ Email : kasnursaptra@gmail.com
}

\begin{abstract}
This tourism information system is built to meet the needs of users to help the Tourism Department in presenting tourism information. In this case, there are various problems using the websites that are still not optimal from the internal and external side in terms of presentation and use. Therefore, the author tries to create a more attractive website appearance to be easily accepted and fascinated for users to visit tourism destinations in Singkawang West Kalimantan. The system is expected to meet the needs of users and effectively reduce the cost of tourism promotion.
\end{abstract}

Keywords: Tourism, Information System, Website, Promotion

\begin{abstract}
ABSTRAK
Sistem informasi pariwisata ini dibangun bertujuan untuk memenuhi kebutuhan pengguna demi membantu Dinas Pariwisata dalam menyajikan informasi pariwisata. Dalam hal ini, terdapat berbagai masalah dalam penggunaan website yang masih belum optimal dari sisi internal dan eksternal dalam hal penyajian dan penggunaannya. Maka dengan itu, penulis mencoba menciptakan sebuah tampilan website yang lebih menarik agar mudah diterima dan menjadi daya tarik bagi pengguna untuk mengunjungi tempat - tempat wisata dan budaya di Singkawang Kalimantan Barat. Sistem di harapkan dapat memenuhi kebutuhan pengguna secara tepat dan relevan serta mengurangi biaya promosi secara berlebihan.
\end{abstract}

Kata Kunci :Pariwisata, Sistem Informasi, Website, Promosi

Pendahulan

Perkembangan pariwisata saat ini dipercepat oleh globalisasi dunia yang mengacu pada perkembangan teknologi informasi sehingga membuat segala informasi tentang pariwisata di suatu daerah mudah di dapat, baik melalui baliho, brosur dan internet. Akan tetapi informasi yang di dapat kadang kurang mewakili kebutuhan dari pengguna. Karena informasi yang diberikan kurang lengkap.

Hal ini disebabkan karena tidak adanya informasi yang akurat serta ketidaktahuan pengunjung dan wisatawan atau calon wisatawan tentang informasi pariwisata dan letak obyek - obyek wisata secara tepat. Teknologi berbasis internet berupa jaringan komputer global yang paling berkembang pesat saat ini. Informasi yang lengkap serta jangkauan yang luas hingga seluruh penjuru dunia dapat di sampaikan lewat media internet.

Hal ini dijadikan solusi yang tepat untuk dipilih sebagai alat dalam penyampaian informasi dan promosi yang baik dilakukan oleh Pariwisata Singkawang - Kalimantan Barat. Salah satu teknologi internet yang dapat digunakan adalah World Wide Web yaitu teknologi berbasis web yang mampu memberikan informasi dalam bentuk teks, gambar, video dan suara.

Suatu harapan dengan hadirnya teknologi internet berbasis web pada Pariwisata Singkawang Kalimantan Barat penyampaian informasi dan promosi dapat dilakukan secara efektif dan efesien. 
Kota Singkawang adalah kota yang dikenal memiliki bermacam - macam kebudayaan dan obyek - obyek wisata yang menarik di Kalimantan Barat.

Selama ini penyampaian informasi melalui baliho, brosur dan media internet belum optimal dan masih terdapat berbagai kelemahan - kelemahan dari sistem tersebut, karena terbatasnya pada ruang lingkup wilayah tertentu, maka dari itu dengan adanya website ini ditujukan untuk lebih memperluas penyampaian informasi dan promosi. Dibangunnya website Pariwisata di Singkawang Kalimantan Barat yang menampilkan tentang informasi pariwisata berupa obyek - obyek wisata dengan berbagai macam wahana, kebudayaan yang berupa kerajinan tangan, adat- istiadat, kul' pelayanan informasi penginapan, pelayanan $s \varepsilon$ prasarana wisata yang mendukung perjalanan wisata dan kegiatan - kegiatan kepariwisataan, serta di harapkan penguna (pengunjung, wisatawan atau calon wisatawan) dapat mengenal kebudayaan dan mempermudah wisatawan menemukan rute jalan atau jalur untuk menuju ke obyek - obyek wisata.

Adanya kemudahan yang di dapat, maka akan menambah jumlah para pengunjung dan wisatawan atau calon wiswatawan yang akan berkunjung untuk berwisata dan mempelajari budaya Kota Singkawang sehingga dapat memberikan konstribusi dalam meningkatnya pendapatan dan daya tarik wisata secara global.

\section{Metode}

Dalam pengembangan pariwisata pada Kota Singkawang, penulis merencanakan membangun sebuah sistem yang berbasis internet sebagai media promosi atas produk yang berupa pariwisata dan budaya serta jasa berupa informasi pendukung yang di sampaikan. Sistem yang akan dibangun nantinya khusus untuk menangani promosi yang bersifat online, sehingga dapat di akases oleh para wisatawan maupun calon wisatawan dengan cakupan wilayah yang lebih luas.

\section{Analisis PIECES}

Untuk mengindentifikasi masalah harus dilakukan analisis terhadap kinerja, informasi, ekonomi, keamanan aplikasi, efisiensi, dan pelayanan pelanggan. Panduan ini dikenal dengan analisis PIECES ( Performance, Information, Economy, Control, Eficiency, dan Services ).

a. Performance (Kinerja), Membutuhkan waktu yang lebih cepat karena masyarakat yang membutuhkan informasi dilayani oleh sistem yang dapat diakses di manapun dan kapan pun.

b. Information (Informasi), Apabila liburan tiba tempat wisata dan hotel lebih mudah didapat karena informasi nya yang selalu update baik untuk tempat wisata dan pemesanan hotel serta fasilitas lainnya sesuai kebutuhan.

c. Economic (Ekonomi), Sistem ini akan memberi penghematan operasional dan meningkatkan penghematan operasional serta meningkatkan keuntungan instansi. Dalam jangka pendek, biaya yang dibutuhkan akan cukup besar. Tetapi untuk jangka panjang lebih sedikit karena hanya mengeluarkan biaya untuk hosting.

d. Control (Pengendalian), Dengan adanya password diharapkan hak akses tergantung pada user sehingga sistem tidak akan dapat di akses oleh sembarang orang.

e. Effeciency (Efesiensi), Sumber daya manusia yang dibutuhkan lebih sedikit karena sudah dibantu dengan sistem, sehingga lebih efisien.

f. Services (Pelayanan), Untuk mendapatkan informasi tidak usah datang ke Singkawang, melainkan masuk pada website Pariwisata Singkawang yang mana semua informasi akan didapatkan dan informasi dapat di akses kapan pun dan dimanapun selagi terdapat koneksi internet

\section{Analisis Kebutuhan Sistem}

Untuk meningkatkan kualitas informasi yang diperlukan, suatu sistem informasi yang dapat diakses kapan saja dan dimana saja secara non stop, maka dibutuhkan teknologi berbasis website yang digunakan sebagai media informasi bagi Dinas Pariwisata Singkawang untuk dapat meningkatkan promosi pariwisata.

\section{Analisis Kebutuhan Fungsional}

Suatu sistem informasi yang bermamfaat bagi pengunjung yaitu sistem informasi promosi berbasis website. Dimana informasi yang disajikan dapat diakses dengan menggunakan internet.

\section{Analisis Kebutuhan Non Fungsional}

Analisis kebutuhan non fungsional dilakukan untuk mengetahui spesifikasi kebutuhan untuk sistem. Spesifikasi kebutuhan melibatkan analisis perangkat keras/hardware,analisis perangkat lunak/software.

\section{a. Analisis Perangkat Keras (Hardware)}

Analsis perangkat keras bertujuan untuk mengetahui secara tepat perangkat keras yang dibutuhkan. Adapun hardware yang 
digunakan penulis dalam pengembangan sistem informasi sebagai berikut :

a) Prosesor : Intel Pentium T2370 (a $1.73 \mathrm{GHz}$

b) Memory : 1.50 GB Dual-Channel DDR2 @ $266 \mathrm{MHz}$

c) Motherboard: Wistron 30CD (U2E1)

d) Hardisk : 117GB

e) Mouse

\section{b. Analisis Perangkat Lunak (Software)}

Analisis perangkat lunak bertujuan untuk mengetahui secara tepat perangkat apa saja yang dibutuhkan menjalankan suatu informasi. Perangkat lunak yang dibutuhkan antara lain :

a) Microsoft Windows XP Professional SP2

b) Adobe Dreamweaver CS3

c) Database MySQL

d) Apache Xampp sebagai web server

e) MySql Sebagai database server

f) Mozilla Firefox sebagai web browser

\section{Kebutuhan Informasi}

Informasi merupakan kebutuhan utama suatu instansi yang nantinya dijadikan sebagai acuan

c. User atau Pengguna

User ini memiliki hak untuk mendapatkan informasi obyek wisata dan juga dapat mengetahui deskripsi tentang obyek wisata yang dibutuhkan. User juga dapat melakukan pemesanan fasilitas.

\section{Analisis Kelayakan Sistem}

Analisis kelayakan digunakan untuk mempertimbangkan aspek-aspek yang terkait dalam pembangunan sebuah sistem, sehingga dapat ditentukan apakah sistem yang dibuat tersebut lebih baik daripada sistem yang sudah ada atau bahkan sebaliknya.

\section{Analisis Kelayakan Teknologi}

Teknologi yang digunakan dalam penerapan website Pariwisata Singkawang ini dapat dikatakan telah mengikuti perkembangan zaman saat ini yang serba digital. Hal ini disebabkan penggunaan teknologi berbasis web yang mudah diakses kapan saja, dimana saja dan oleh siapa

Kelayakan ekonomi akan menganalisis biaya yang akan dikeluarkan oleh Dinas Pariwisata Singkawang yang akan datang serta mamfaat yang akan didapat dari penerapan sistem baru dibanding sistem lama, sehingga tidak akan terjadi pemborosan sumber daya lagi. untuk pimpinan dalam mengambil keputusan. Informasi yang dibutuhkan adalah sebagai berikut :

a. Informasi mengenai obyek-obyek wisata yang ada pada pariwisata singkawang

b. Informasi promosi yang dilakukan instansi

c. Informasi mengenai berbagai masukan dari pengunjung tentang pariwisata yang di sajikan dan pelayanan instansi

\section{Kebutuhan Pengguna (User)}

a. Programmer

Orang yang bertugas membuat sistem serta melakukan maintenance dan melakukan perbaikan jika terjadi kesalahan atau kerusakan sistem.

b. Administrator

Admin memiliki akses penuh dalam melakukan pengaturan sistem. Admin dapat melakukan input, edit, delete dan update data wisata. Tidak setiap user memiliki hak yang sama dengan admin, hal tersebut dimaksudkan untuk menjaga keamanan dan keaslian informasi yang diberikan sistem.

saja sehingga informasi tentang Pariwisata Singkawang dapat lebih cepat sampai kepada user yang membutuhkan.

\section{Analisis Kelayakan Hukum}

Sistem baru ditawarkan hanya berkaitan dengan informasi tentang Pariwisata Singkawang, sehingga tidak melanggar hukum karena tidak terpaut denagn hal-hal yang melanggar SARA ( Suku, Adat, Ras, dan Agama) ataupun pornografi.

\section{Analisis Kelayakan Operasional}

Sistem ini tidak membutuhkan operator dengan keahlian khusus untuk dapat mengoperasikannya, hanya saja agar penggunaan sistem dapat lebih optimal maka bagian yang akan menangani atau mengatur sistem (admin) akan diberikan pelatihan untuk menambah kemampuan dasar dalam mengeoperasikan sistem.

\section{Analisis Kelayakan Ekonomi}

Hasil

\section{Pembuatan Basis Data}

Pembuatan basis data menggunakan MySQL dan memanfaatkan phpMyAdmin sebagai antarmuka, dimana keduanya terdapat didalam bundling XAMPP. Pembuatannya meliputi basis data itu sendiri dan tabel - tabel di dalam nya. 


\section{Uji Coba Program}

Uji coba program dilakukan untuk mengetahui apakah program dapat berinteraksi dengan baik. Selain itu, pengetesan program bertujuan untuk menghindari kesalahan - kesalahan dalam program sebelum program tersebut diterapkan dalam sistem yang resmi. Kesalahan dalam program terbagi menjadi tiga, antara lain :

1. Kesalahan bahasa (language error)

Disebut juga kesalahan sintaks ( syntax error) adalah kesalahan yang terdapat pada penulisan kode program yang tidak sesuai dengan yang disyaratkan.

2. Kesalahan sewaktu proses (run- time errors), adalah kesalahan yang terjadi sewaktu proses executable program dijalankan.

\section{Kesalahan logika (logical error)}

Adalah kesalahan yang terjadi pada penentuan logika program. Tidak ada peringatan oleh compiler karena pada dasarnya sintaks dan kondisi sudah benar.

\section{Manual Program}

\section{a. Halaman Control Panel Administrator}

Control panel administrator digunakan oleh admin utama dalam mengelola website secara keseluruhan. Penggunaan gambar pada bagian ini memang tidak terlalu dibutuhkan. Penempatan logo dan warna khas pariwisata singkawang seperti halaman utama website.

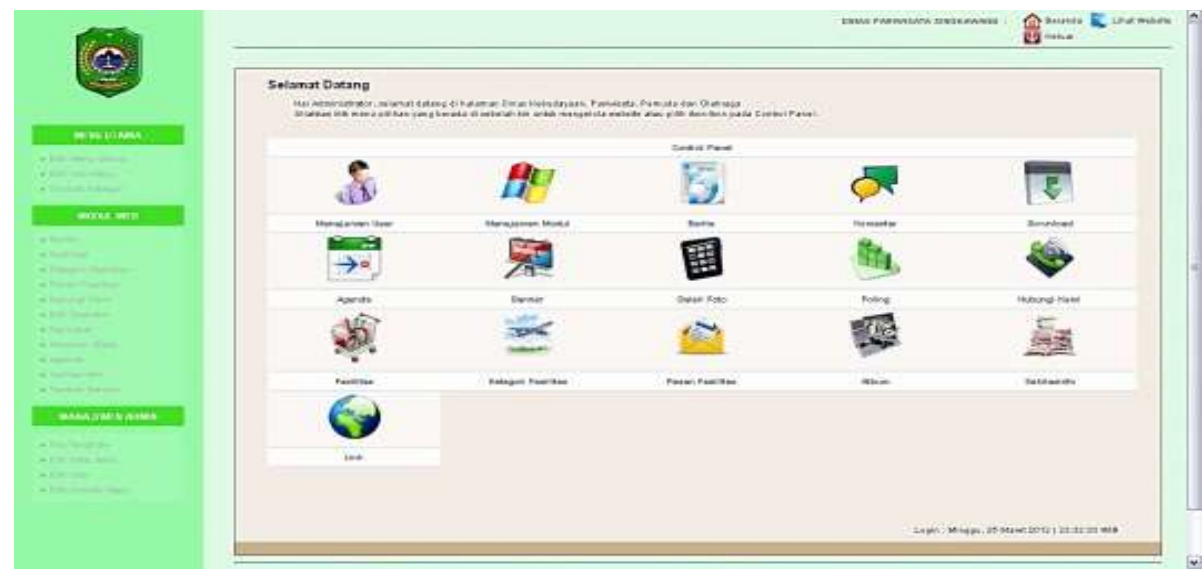

Gambar 1. Tampilan Home Admin (Data diolah, 2013)

\section{b. Halaman user admin}

User yang telah diberikan hak akses untuk dapat masuk kedalam halaman admin, adalah patner yang bekerja sama dengan admin untuk dapat mengelola website ini dengan baik. Bagian body sebenarnya sama dengan halaman admin untuk level admin, hanya saja untuk user admin dibatasi hak aksesnya. Pembuatannya sama seperti yang dilakukan pada tampilan halaman utama admin. Sedangkan bagian menu disesuaikan dengan hak akses user tersebut.

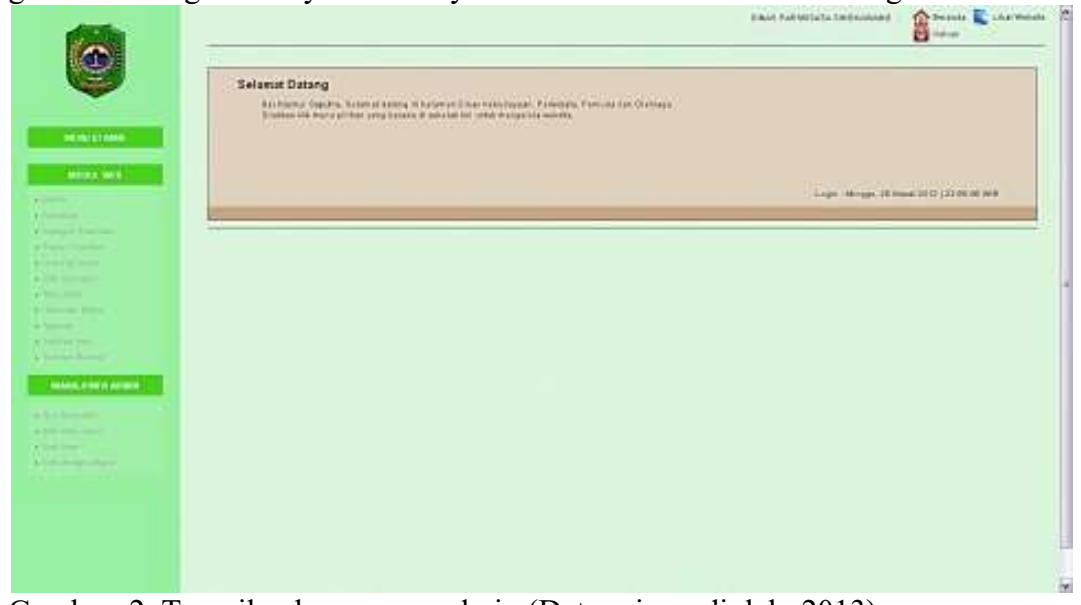

Gambar 2. Tampilan home user admin (Data primer diolah, 2013) 


\section{c. Tampilan Beranda}

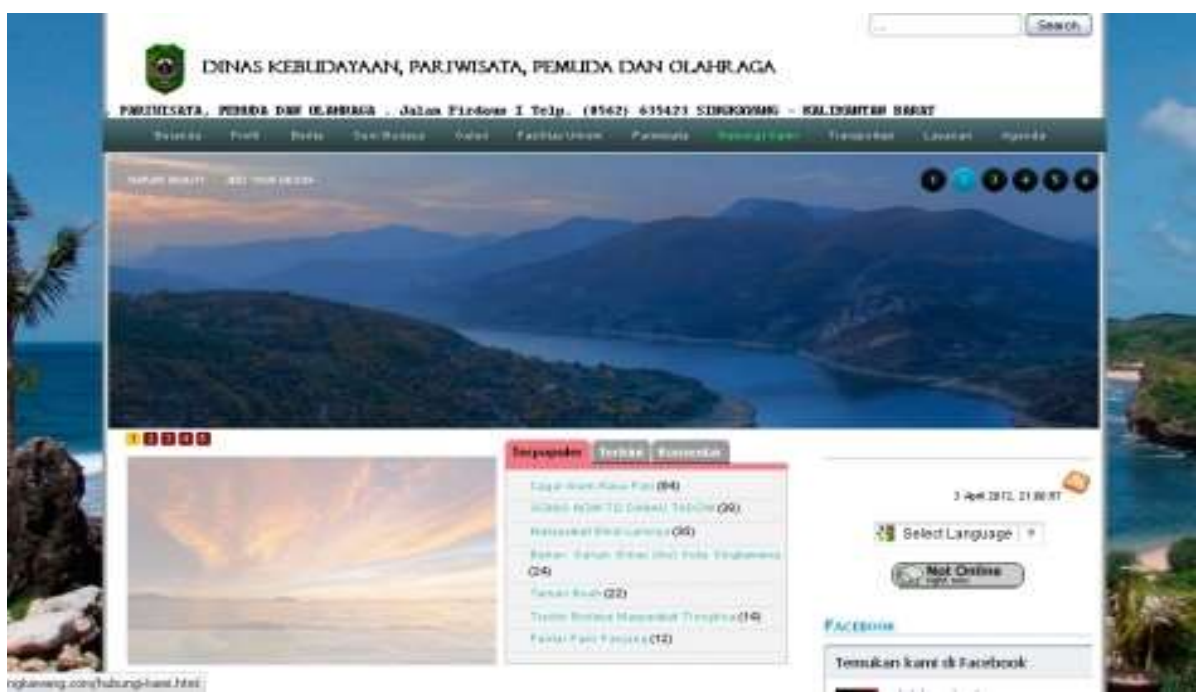

Gambar 3. Tampilan Utama Halaman Beranda (Data diolah, 2013)

Pada halaman beranda, informasi yang ditampilkan antara lain obyek wisata yang akan dijadikan headline menarik, link obyek wisata yang sering dikunjungi, komentar - komentar para pengunjung website, fasilitas yang disediakan yang dapat melakukan pemesanan melewati admin, agenda kepariwisataan, tidak ketinggalan statistik pengunjung.

\section{d. Pembahasan Program}

\section{a) Module dan Act}

Pembuatan website ini memamfaatkan metode \$_GET[ ] untuk menavigasi alamat url dengan menggunakan module dan act sebagai nilai yang menentukannya. Module menyisipkan halaman lain dengan menggunakan fungsi include, sedangkan act untuk menentukan aksi.

\section{b) Keamanan}

Keamanan merupakan hal diperhatikan di dalam membangun sebuah website. Dewasa ini, dengan perkembangan internet yang meningkat, cara untuk menembus sistem keamanan sebuah website juga semakin beragam. Beberapa trik keamanan yang penulis terapkan pada website antara lain :

1. Mencegah spam dengan kode verifikasi

2. Mencegah serangan XSS

3. Mencegah Injection

\section{e. Pemeliharaan Sistem}

Pemeliharaan dilakukan untuk perangkat sistem ataupun sistem itu sendiri. Hal ini bertujuan agar sistem dapat berjalan dengan baik. Pemeliharaan perangkat sistem sendiri dimulai dari perangkat keras dimana sistem dijalankan dan dikontrol. Pemeliharaan sistem dapat dilakukan dengan cara :

1. Backup data

2. Update content

3. Monitor Statistik Website

4. Promosi Website

\section{Kesimpulan}

1. Aplikasi website yang dibangun mampu memenuhi kebutuhan informasi yang bersifat dinamis karena konten baru bisa ditambahkan oleh administrator dan sebagian oleh user admin setiap saat.

2. Aplikasi website yang dibangun mampu menjadi panduan pariwisata di Singkawang Kalimantan Barat.

3. Informasi yang disampaikan sudah cukup memenuhi kebutuhan informasi mengenai lokasi wisata. Dan untuk lebih jelasnya bisa menghubungi admin biar bisa dijelaskan lebih lanjut.

4. Fasilitas yang berikan sudah cukup memenuhi kebutuhan pengunjung atau calon pengunjung. Dan untuk untuk lebih jelasnya bisa menggunakan form - form yang sudah disediakan di konten website.

5. Dengan website ini maka akan dapat mengurangi biaya promosi konvensional yang sangat besar, karena tidak perlu mengikuti pameran pariwisata di luar daerah.

6. Dengan adanya website ini juga kebutuhan pengunjung dan calon pengunjung terpenuhi untuk mencari data - data yang lengkap terhadap pariwisata yang ada di Singkawang Kalimantan Barat. 
Jurnal Ekonomi dan Bisnis Indonesia

\section{Daftar Pustaka}

Jogiyanto, H.M. 2005. Analisis dan Sistem Informasi, Yogyakarta.

Kristanto,Andri.2003. Perancangan Sistem Informasi dan Aplikasinya, Yogyakarta : Gava Media

Al- Fatta, Hanif. 2007.Analisis dan Perancangan Sistem, Yogyakarta : Andi Offset

Marlina, Linda. Sistem Basis Data, Yogyakarta : Andi Offset
Nugroho, Bunafir . Database Relasional dengan MySQL , Yogyakarta : Andi Offset

Hakim, Lukmanul, 2008. Tips dan Trik Pemrograman PHP, Yogyakarta : LokomediaHakim,

Lukmanul, 2010. Bikin Website Super Keren dengan PHP dan jQuery, Yogyakarta : Lokomedia

Purbo,W,O.http://kambing.ui.ac.id/bebas/v09/onno -ind-1/application/cuplikan-sejarahinternet-indonesia-05-2000.rtf 